\title{
Response of broiler chicks to L-Glutamine feeding in the Immediate pre- and post- hatch periods
}

\author{
S. Karamik \& C. Kop-Bozbay \\ Department of Animal Science, Faculty of Agriculture, Eskisehir Osmangazi University, 26480, Eskisehir, Turkey
}

(Submitted 31 August 2020; Accepted 10 October 2020; Published 29 November 2020)

\author{
Copyright resides with the authors in terms of the Creative Commons Attribution 4.0 South African Licence. \\ See: http://creativecommons.org/licenses/by/4.0/za \\ Condition of use: The user may copy, distribute, transmit and adapt the work, but must recognise the authors and the South African \\ Journal of Animal Science.
}

\begin{abstract}
This study was conducted to investigate the effects of in ovo and post-hatching supplementation with L-Glutamine (Gln) on hatching characteristics, performance, small intestinal morphology, and muscle development of broilers. At day 18 of incubation, 960 fertilized eggs were allocated to four treatments with six replicates. Eggs were i) not injected (negative control) (NC), ii) subject to the standard incubation procedure (PG), iii) injected with $1 \mathrm{ml}$ sterile solution with $0.9 \%$ salt (positive control) (PC), and iv) injected with $1 \%$ Gln solution (IG). On hatching, the SC chicks were fed with $1 \%$ Gln for seven days. The remaining chicks were fed a commercial starter feed. After hatching, there were six replicates of 28 birds in each treatment. Hatchability and yolk sac weight were lower and yolk-free chick weight (YFCW), whole gastrointestinal tract (GIT) and breast muscle weights were higher at hatching for chicks from the IG treatment. At 42 days old, feed conversation ratio (FCR) was lower in birds that had Gln added to their diet than for the other treatments. The FCR was also lower in IG birds than birds in the NC group. The GIT weight, villus height, villus width and crypt depth of the birds receiving dietary supplementation of Gln were greater than those of birds in PC and IG. Thus, in ovo injection of GIn improved hatching characteristics except for hatchability. Further, in ovo and dietary Gln administration reduced FCR by stimulating digestive system development.
\end{abstract}

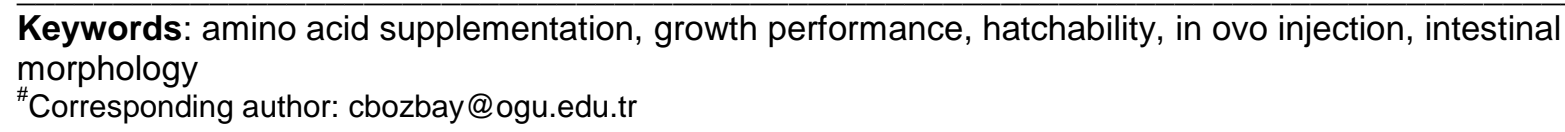

\section{Introduction}

To ensure high productivity in poultry, the nutrient needs of chicks should be met in a balanced and complete manner during embryonic development and in the early stages of post-hatch life. Early feeding strategies are used to minimize the physiological changes caused by the delay in access to feed and water from the hatching period until the chicks can be placed with the hens where they will be reared. These applications can be performed by intra-egg injection (in ovo feeding) and during immediate post-hatch feeding. Both applications result in improvements in poultry performance (Kucharska-Gaca, et al., 2017; Kop-Bozbay \& Ocak, 2019, 2020). However, in general, the effects on these parameters of in ovo and early feeding were investigated individually in scientific studies, and the number of scientific studies that compare feeding strategies, within the same study, are limited (Atan \& Kop-Bozbay, 2019).

The nutrient requirements of broilers with high genetic potential for growth are challenging during incubation and post hatch. One of the most important factors that affect performance in broilers is the healthy completion of digestive system development (Maiorka et al., 2005). This is important to ensure the realization of growth potential (Uni \& Ferket, 2004). Therefore, the transition period from pre-hatch (Uni \& Ferket, 2004) to one week after hatching (Maiorka et al., 2016) should be managed well. L-Glutamine is an amino acid that stimulates development of the intestine and its mucosa in broilers (Wu, 2009; Xue et al., 2018). Chickens fed rations supplemented with Gln reportedly had greater intestinal weight, higher intestinal villi and deeper crypts (Yi et al., 2005; Bartell \& Batal, 2007; Fischer da Silva et al., 2007; Murakami et al., 2007; Soltan, 2009). However, although there are studies in which Gln was used in the immediate pre-hatch diet (Chen et al., 2009; Salmanzadeh et al., 2016; Youssef et al., 2017) and post hatch (Dai et al., 2009; Soltan, 2009; Salmanzadeh \& Shahryar, 2013; Gholipour et al., 2018), no study has compared the effects of these two 
feeding strategies.

Differences between a negative control treatment and a positive control, and the effects of in ovo treatments on hatching characteristics have been demonstrated. However, differences between these treatments and standard incubation procedure have not been investigated. Therefore, the objectives of this study were to determine the effects of i) in ovo Gln feeding on hatching characteristics, ii) in ovo or dietary Gln administration on performance, small intestinal morphology and muscle development of broilers, and iii) sham in ovo injection on hatching characteristics.

\section{Materials and Methods}

All the procedures with animals were approved by the Local Ethics Committee of Animal Experiments of Eskisehir Osmangazi University (Protocol no. HAYDEK-642/2018). A total of 960 fertile Ross 308 eggs of approximately similar weights $(46.7 \pm 1 \mathrm{~g})$ were obtained from a commercial company (CP Group, Istanbul, Turkey).

The eggs were incubated under optimal conditions $\left(37.7{ }^{\circ} \mathrm{C}-37.2{ }^{\circ} \mathrm{C}\right.$ and $60 \%-75 \%$ humidity) at the Research and Application Farm of Agricultural Faculty of Eskişehir Osmangazi University. At day 18 of incubation, the eggs were candled and those eggs containing viable embryos were allocated randomly to four treatments with six replicates of 40 eggs per tray. The treatments consisted of i) an untreated negative control (NC), ii) a positive control in which the eggs were injected with $1 \mathrm{ml}$ sterile solution with $0.9 \%$ salt (PC), iii) eggs that were injected with a $1 \%$ Gln solution (IG), and (iv) the chicks from untreated eggs, which received dietary supplementation with $10 \mathrm{~g} / \mathrm{kg} \mathrm{Gln}$ for seven days after hatching (PG). For the IG treatment, a sterile solution with $0.9 \%$ salt was prepared (Foye et al., 2006). Then, $1 \mathrm{~g}$ Gln (Sigma Aldrich No. H8125 and A9920; Merck KGaA, Darmstadt, Germany) was dissolved completely in the sterile solution to produce $100 \mathrm{ml}$ of solution containing approximately $1 \mathrm{~g}$ Gln. The IG treatment was applied by manual injection into the amniotic fluid with a $19 \mathrm{~mm}$ and 27-gauge needle (Uni et al., 2005). After injection, the holes in the eggshells were sealed immediately with liquid paraffin, and the eggs were transferred to hatching baskets in the incubator. The NC, PC, and IG eggs were treated similarly. Eggs from PG were placed in the incubator immediately after being candled, and standard incubation procedures were applied.

On hatching, some of the chicks were transferred to an experimental house with six replicates of 28 birds (14 females and 14 males) with similar average weights $(42 \pm 3 \mathrm{~g})$ and reared for 42 days. All groups were fed ad libitum with corn-soybean-based commercial diets through 42 days old (Table 1), except that the PG chicks were given the feed supplemented with Gln for the first seven days post hatch. All birds were reared on the floor pens $(2.5 \mathrm{~m} \times 1.0 \mathrm{~m} \times 4.5 \mathrm{~m})$ with wood shavings. The pens contained a poultry feeder plate and automatic drinkers.

To determine embryonic weight at day 18 of incubation and the weights of the chicks, organs, and tissues at hatching, 12 embryonated eggs and 12 chicks were randomly selected from each treatment. The day 18 yolk-free embryos and the yolk-free newly hatched chicks were weighed individually and the gain between day 18 of incubation and hatching was calculated. At hatch, the yolk sac (YS) and whole GIT were removed carefully from the abdominal cavity and measured. The lliotibialis muscle (ITM) and Pectoralis major muscle (PM) were also removed carefully from the carcass and weighed (Kop-Bozbay \& Ocak, 2019). The relative weights of YS, GIT, ITM, and PM were calculated as percentages of bodyweight $(\mathrm{g}$ or $\mathrm{cm} / 100$ g).

At hatch, the chicks and all unhatched eggs were counted, and the percentage hatchability of fertile eggs was calculated. All unhatched eggs were opened and examined macroscopically for indicators of physiological processes (dead with pipping or dead without pipping). Dead poults in each class were expressed as the percentages of incubated fertile eggs.

Feed intake (FI) was measured for the entire experiment and recorded for each pen. Bodyweight was recorded at 42 days old. Feed conversion ratio ( $\mathrm{g}$ feed to $\mathrm{g}$ gain) was calculated from the bodyweight and feed consumption for each pen.

To determine the weights of the GIT, ITM, PM, and small intestine segments, such as duodenum, jejunum and ileum, 12 birds per treatment (one female and one male per repetition) were selected, weighed, and killed by cervical dislocation, at 42 days old (Maiorka, 2003). The relative weights of the organs and tissues at day 42 were calculated as percentages of bodyweight ( $\mathrm{g} / 100 \mathrm{~g}$ bodyweight). Subsequently, tissue samples were collected from the duodenum, jejunum, and the ileum (Gholipour et al., 2018) to evaluate intestinal morphology (villus height, villi width, and crypt depth). These sections were fixed in $10 \%$ formalin buffer solution after extraction, washed with physiological serum $(0.9 \%$ salt), and placed in a histolectric device for processing. After paraffin moulding, five micrometre sections were prepared from each sample, and the samples were stained with haematoxylin and eosin and observed under a computer-connected light microscope (Zeiss-Scope A1;Carl-Zeiss-Promenade, Jena, German ) (lji et al., 2001).

One-way analysis of variance used to determine the effect of the treatments on the variables using the 
Windows version of SPSS (SPSS Inc., Chicago, Illinois, USA). Differences between the treatments were considered significant at $P<0.05$. The normal distribution of the data was evaluated with the Levene test and homogeneity of variance was tested with the Kolmogorov-Smirnov test. Differences between treatments were assessed by Duncan's multiple comparison test when the overall treatment effect was significant.

Table 1 Ingredients and calculated nutrient values of basal diets for broiler chickens

\begin{tabular}{lcc}
\hline Ingredients $(\mathrm{g} / \mathrm{kg})$ & Starter $(0-21 \mathrm{~d})$ & Finisher $(21-42 \mathrm{~d})$ \\
\hline & 555.75 & 586.88 \\
Corn & 380.00 & 330.00 \\
Soybean meal (46\% crude protein) & 25.00 & 45.08 \\
Vegetable oil & 19.39 & 19.61 \\
Dicalcium phosphate & 8.75 & 7.31 \\
Limestone & 3.61 & 3.61 \\
Sodium chloride & 2.50 & 2.50 \\
Lysıne-Hcl & 2.50 & 2.50 \\
DI-Metionıne & 2.50 & 2.50 \\
Vitamin-mineral premix ${ }^{1}$ & & \\
\hline Calculated nutrient analysis & 3038.00 & 3190.00 \\
Metabolizable energy, Kcal.kg & 88.81 & 89.09 \\
Dry matter, g/kg & 21.85 & 19.76 \\
Crude protein, g/kg & 4.50 & 6.52 \\
Crude oil, g/kg & 2.90 & 2.78 \\
Crude fibre, g/kg & 6.17 & 5.78 \\
Ash. g/kg & 1.50 & 1.15 \\
Lysine, g/kg & 0.57 & 0.51 \\
Methionine, g/kg & 0.92 & 0.86 \\
Methionine+Cysteine, g.kg & 0.24 & 0.21 \\
D-Tryptophan, g/kg & 0.96 & 0.90 \\
Calcium, g/kg & 0.40 & 0.40 \\
Available phosphorus, g/kg & & \\
\end{tabular}

\footnotetext{
${ }^{1}$ Vitamin $A: 12000 \mathrm{IU}$, vitamin $\mathrm{D}_{3}: 2400 \mathrm{IU}$, vitamin $\mathrm{E}: \mathrm{IU}$, vitamin $\mathrm{K}_{3}: 2.5 \mathrm{mg}$, vitamin $\mathrm{B}_{1}: 3.0 \mathrm{mg}$, vitamin $\mathrm{B} 2: 7 \mathrm{mg}$, nicotinamide: $40 \mathrm{mg}$, calcium d-pantothenate: $8.0 \mathrm{mg}$, vitamin $\mathrm{B}_{6}: 4.0 \mathrm{mg}$, vitamin $\mathrm{B}_{12}: 0.015 \mathrm{mg}$, folic acid: $\mathrm{mg}$, D-biotine: $0.045 \mathrm{mg}$; vitamin C: $50 \mathrm{mg}$; chlorine chloride: $125 \mathrm{mg}$, manganese: $80 \mathrm{mg}$, iron: $40 \mathrm{mg}$, zinc: $60 \mathrm{mg}$, copper: $5 \mathrm{mg}$, cobalt: $0.1 \mathrm{mg}$, iodine: $0.4 \mathrm{mg}$, selenium: $0.15 \mathrm{mg}$
}

\section{Results and Discussion}

Hatchability was reduced by IG compared with NC and PG $(P<0.05)$, which, as expected, were similar. Embryos fed Gln had a higher weight gain than those in PC $(P<0.05)$. The yolk-free weight of embryos in IG was higher than in $P G(P<0.01)$. The $Y S$ of the IG group had a lower relative weight than for chicks from PG $(P<0.05)$. The IG treatment increased the relative weight of the PM compared with $P C$ and PG $(P<0.05)$, and that of the GIT compared with all other groups at hatch $(P<0.001)$. The results for hatchability are presented in Table 2.

The FI and BW of birds at 42 days old were not affected by the treatments (Table 3). However, the FCR was lower in the PG birds than in the birds that did not receive supplemental Gln after hatching. The FCR was also lower for IG birds than for those in the NC group $(P<0.001)$.

At 42 days old, birds in the PG treatment had an increased relative weight of the GIT, compared with $P C$ and IG. In contrast, birds in IG had increased relative weight of the duodenum in comparison with those in $P G(P<0.05)($ Table 4). 
Table 2 Influence of in ovo injection of L-Glutamine on the hatchability and hatchability traits

\begin{tabular}{lcccccc}
\hline Variable & NC & PG & PC & IG & SE & $P$-value \\
\hline Hatchability of fertile eggs, \% & $93.70^{\mathrm{a}}$ & $91.59^{\mathrm{a}}$ & $90.43^{\mathrm{ab}}$ & $86.85^{\mathrm{b}}$ & 0.86 & 0.018 \\
Percentages of dead-in-shell chicks, \% & & & & & & \\
$\quad$ Pipped & 1.33 & 1.00 & 2.00 & 2.00 & 0.28 & 0.624 \\
$\quad$ Non-pipped & 3.93 & 7.31 & 5.03 & 9.68 & 0.85 & 0.056 \\
Bodyweight change, g & $16.68^{\mathrm{ab}}$ & $15.63^{\mathrm{ab}}$ & $13.20^{\mathrm{b}}$ & $18.28^{\mathrm{a}}$ & 0.74 & 0.050 \\
Yolk-free chick weight, g & $35.59^{\mathrm{ab}}$ & $34.67^{\mathrm{b}}$ & $36.26^{\mathrm{ab}}$ & $40.34^{\mathrm{a}}$ & 0.87 & 0.001 \\
Relative weights of (g/100 g bodyweight) & & & & & & \\
$\quad$ Yolk sac & $15.32^{\mathrm{ab}}$ & $17.81^{\mathrm{a}}$ & $14.04^{\mathrm{ab}}$ & $11.42^{\mathrm{b}}$ & 0.87 & 0.047 \\
$\quad$ Gastrointestinal tract & $5.99^{\mathrm{b}}$ & $6.05^{\mathrm{b}}$ & $5.97^{\mathrm{b}}$ & $7.47^{\mathrm{a}}$ & 0.55 & $<0.001$ \\
$\quad$ Thigh muscle & 5.67 & 6.04 & 5.68 & 6.15 & 0.11 & 0.101 \\
$\quad$ Breast muscle & $1.62^{\mathrm{ab}}$ & $1.55^{\mathrm{b}}$ & $1.50^{\mathrm{b}}$ & $1.67^{\mathrm{a}}$ & 0.04 & 0.024
\end{tabular}

a,b Within a row, means with a common superscript were not different at $P=0.05$

PC: eggs injected with $1 \mathrm{ml}$ sterile solution; NC: eggs not injected; IG: eggs injected with $1 \mathrm{ml}$ sterile solution containing L-Glutamine; PG: eggs subjected to standard incubation procedure

Table 3 Influence of in ovo or dietary L-Glutamine administration on the performance of broiler chickens

\begin{tabular}{lcccccc}
\hline Variables & NC & PG & PC & IG & SE & $P$-value \\
\hline Feed intake, g & 4713.25 & 4628.25 & 4669.5 & 4697.75 & 50.26 & 0.951 \\
Bodyweight, g & 2560.55 & 2570.60 & 2548.50 & 2577.60 & 29.98 & 0.989 \\
Feed conversion ratio, g feed/g gain & $1.84^{\mathrm{a}}$ & $1.80^{\mathrm{c}}$ & $1.83^{\mathrm{ab}}$ & $1.82^{\mathrm{b}}$ & 0.01 & $<0.001$ \\
\hline
\end{tabular}

$\overline{a, b}$ Within a row, means with a common superscript were not different at $P=0.05$

PC: eggs injected with $1 \mathrm{ml}$ sterile solution; NC: eggs not injected; IG: eggs injected with $1 \mathrm{ml}$ sterile solution containing L-Glutamine; PG: eggs subjected to standard incubation procedure with the chicks receiving L-Glutamine post hatch

Table 4 Influence of in ovo or dietary L-Glutamine administration on the relative weights $(\mathrm{g} / 100 \mathrm{~g}$ bodyweight) of digestive organs, breast, and thigh muscle in broiler chickens

\begin{tabular}{lcccccc}
\hline Relative weights & NC & PG & PC & IG & SE & $P$-value \\
\hline Gastrointestinal tract & $6.77^{\mathrm{ab}}$ & $7.55^{\mathrm{a}}$ & $6.36^{\mathrm{b}}$ & $6.40^{\mathrm{b}}$ & 3.86 & 0.022 \\
Duodenum & $7.95^{\mathrm{ab}}$ & $7.63^{\mathrm{b}}$ & $9.09^{\mathrm{ab}}$ & $10.39^{\mathrm{a}}$ & 0.64 & 0.034 \\
Jejunum & 19.51 & 18.77 & 19.21 & 18.65 & 1.26 & 0.919 \\
Ileum & 14.22 & 13.63 & 15.37 & 13.27 & 1.10 & 0.653 \\
Thigh muscle & 8.03 & 7.90 & 7.90 & 7.91 & 3.48 & 0.984 \\
Breast muscle & 11.46 & 12.75 & 12.05 & 11.77 & 6.41 & 0.156 \\
\hline
\end{tabular}

${ }^{a, b}$ Within a row, means with a common superscript were not different at $P=0.05$

PC: eggs injected with $1 \mathrm{ml}$ sterile solution; NC: eggs not injected; IG: eggs injected with $1 \mathrm{ml}$ sterile solution containing

L-Glutamine; PG: eggs subjected to standard incubation procedure with the chicks receiving L-Glutamine post hatch

In the duodenum, the villus length of $P G$ was greater than that of t NC $(P<0.05)$, and the crypt depth of the PG birds was higher than that of the controls $(P<0.05)$. The villus length and crypt depth of the birds in the NC treatment were lower than birds in the other treatments $(P<0.05)$. The villus width in the jejunum of 
NC birds was lower than all birds supplemented with $\operatorname{Gln}(P<0.05)$. At the distal end of the small intestine (ileum), the villus length of PG birds was greater than that of PC and NC birds $(P<0.001)$ and the crypt depth in the ileum of birds in the NC treatment was lower than that of birds in the other treatments $(P<0.05)$. The effects of immediate pre- and post-hatch Gln supplementation on small intestinal morphology at 42 days old are shown in Table 5.

Table 5 Influence of in ovo or dietary L-Glutamine administration on villus length, villus width and crypt depth of duodenum, jejunum, and ileum in broiler

\begin{tabular}{lcccccc}
\hline Instestinal characteristics & NC & PG & PC & IG & SE & $P$-value \\
\hline Duodenum & & & & & & \\
$\quad$ Villus length & $1322.64^{\mathrm{b}}$ & $1650.05^{\mathrm{a}}$ & $1480.23^{\mathrm{ab}}$ & $1531.01^{\mathrm{ab}}$ & 42.169 & 0.028 \\
$\quad$ Villus width & 177.98 & 202.68 & 182.98 & 196.68 & 4.082 & 0.096 \\
$\quad$ Crypt depth & $198.25^{\mathrm{b}}$ & $249.07^{\mathrm{a}}$ & $211.57^{\mathrm{b}}$ & $222.69^{\mathrm{ab}}$ & 6.347 & 0.013 \\
Jejunum & & & & & & \\
$\quad$ Villus length & $1140.82^{\mathrm{b}}$ & $1561.56^{\mathrm{a}}$ & $1365.10^{\mathrm{a}}$ & $1438.46^{\mathrm{a}}$ & 49.080 & 0.005 \\
$\quad$ Villus width & $163.06^{\mathrm{c}}$ & $208.10^{\mathrm{a}}$ & $181.15^{\mathrm{bc}}$ & $197.89^{\mathrm{ab}}$ & 5.368 & 0.003 \\
$\quad$ Crypt depth & $182.65^{\mathrm{b}}$ & $220.23^{\mathrm{a}}$ & $210.04^{\mathrm{a}}$ & $208.53^{\mathrm{a}}$ & 4.110 & 0.001 \\
lleum & & & & & & \\
$\quad$ Villus length & $1092.26^{\mathrm{c}}$ & $1507.78^{\mathrm{a}}$ & $1353.32^{\mathrm{b}}$ & $1423.64^{\mathrm{ab}}$ & 42.708 & $<0.001$ \\
$\quad$ Villus width & 166.92 & 190.60 & 189.92 & 194.39 & 5.993 & 0.382 \\
$\quad$ Crypt depth & $165.51^{\mathrm{b}}$ & $203.10^{\mathrm{a}}$ & $190.55^{\mathrm{a}}$ & $189.43^{\mathrm{a}}$ & 4.255 & 0.003 \\
\hline
\end{tabular}

${ }^{\mathrm{a}, \mathrm{b}}$ Within a row, means with a common superscript were not different at $P=0.05$

PC: eggs injected with $1 \mathrm{ml}$ sterile solution; NC: eggs not injected; IG: eggs injected with $1 \mathrm{ml}$ sterile solution containing L-Glutamine; PG: eggs subjected to standard incubation procedure with the chicks receiving L-Glutamine post hatch

In the present study, in ovo Gln feeding affected hatchability negatively, as was also reported by Salmanzadeh et al. (2016) which differed from the results reported by Youssef et al. (2017). Youssef et al. (2017) injected a $0.2 \mathrm{ml}$ solution (with $5 \mathrm{mg} \mathrm{Gln}$ ) into each egg in their study, whereas Salmanzadeh et al. (2016) injected a $0.5 \mathrm{ml}$ solution (with 10, 20,30, 40, and $50 \mathrm{mg}$ of Gln) into each egg. In the current study, $10 \mathrm{mg}$ Gln, dissolved in $1 \mathrm{ml}$ of solution, was injected into each egg. Nutrient specificity and the osmolarity of the vaccine diluent in the in ovo studies may result in different responses among the embryos (Uni \& Ferket 2003, Salmanzadeh et al., 2016; Kop-Bozbay \& Ocak, 2019). Therefore, the quantity of solution could be detrimental to the internal environmental sensitivity of the embryo and might have a negative effect on hatchability.

Studies have shown that in ovo feeding affects the chick's physiology, nutrient reserve and use of the YS in embryonic development and improves post-hatch growth performance (Soltan, 2009; Salmanzadeh et al., 2016; Kriseldi, 2017). In this study, the in ovo Gln injection increased YFCW and weight gain at hatch. The IG chicks had a lower YS weight and a higher GIT weight at hatch, which supported the concept that the concentration of amino acids in the egg was insufficient to support embryo development in late incubation (Ohta et al., 1999). This observation suggests that embryos that underwent IG treatment had an exogenous feed source earlier than other groups, which encouraged digestive system development and improved YS utilization. The height, width, and area of the villus in the small intestine are considered important indicator parameters for the functionality of the small intestine (Awad et al., 2009). Unfortunately, small intestine morphology was not investigated at hatching of the chicks. However, based on the findings of hatching properties (Table 2), it can be inferred that by stimulating the development of these morphological features, nutrients can be used more effectively. Thus, improved utilization of the YS and the weight of the GIT, PM and CW might encourage general weight gain (Awad et al., 2006). Indeed, the exogenous Gln source may have been beneficial to the development of the GIT, since endogenous Gln production was insufficient to meet body needs (Lobley et al., 2001). In addition, the increased PM weight at hatch after in ovo Gln feeding may be because of the improved amino acid utilization of the embryo. These changes indicated that in ovo Gln injection increased embryonic growth.

In the present study, the results of hatching characteristics of chicks that underwent the NC and PG 
treatments revealed no differences. Therefore, the current results support the idea that standard incubation procedures can be applied without creating negative control groups, which saves time and labour.

The effects of GIn in either in ovo or in the starter feed on FI and BW were not observed in this study. These results are contrary to previous reports (Bartell \& Batal, 2007; Salmanzadeh, et al., 2016; Gholipour, et al., 2018; Xue et al., 2018; Abdulkarimi et al., 2019).However, the FCR was lower among the PG birds than those that underwent the other treatments and was lower among IG than NC. This positive effect can be explained by the increase in weight of the GIT and duodenum, which was evidence of the accuracy of Gln administration, demonstrating the effects of the starter feed on the digestive system (Yi et al., 2005, Bartell \& Batal, 2007; Kriseldi, 2017; Gholipour et al., 2018; Barekatain, 2019).

L-Glutamine plays a role in increasing muscle mass and weight (Watford \& Wu 2005). In the present study, contrary to the findings of Chen et al. (2009) and Gholipour et al. (2018), beneficial effects of Gln supplementation on muscle weight were not detected. The Gln doses and the duration of treatment in the current study may have been insufficient to support the development of muscles.

The results for crypt depth, villus width and villus height (Table 5) show that Gln was used as an energy source for increased intestinal villus height and total mucosal development, stimulated small intestinal cell proliferation, and thus enhanced the absorption surface of the mucosa in the digestive system, increasing the use of nutrients (Caspary, 1992). As a result, it may be concluded that Gln decreases FCR by stimulating the digestive system.

The effects of Gln administration in this study showed that dietary Gln feeding post hatch was more effective. This could be because villus development in all areas of the small intestine is completed early post hatch, within 14 days (Uni et al., 1998) to 21 days (lji et al., 2001). Therefore, in this study, the effect of dietary Gln supplementation on the morphological characteristics of the small intestine may have been seen more clearly.

\section{Conclusions}

In ovo Gln supplementation improved embryo development and hatching characteristics, whereas hatchability was depressed. There were no differences in hatching characteristics between the treatments that did not entail injection of the eggs, namely IG and PG. In ovo and dietary Gln administration reduced FCR by stimulating digestive system development without affecting FI and BW. Since small intestine morphology developments are faster in the post-hatching period of the chick, the development of the digestive system can be promoted by using L-Glutamine during early feeding.

\section{Acknowledgements}

This research was the M.Sc. project of first author and was supported by the Scientific Research Fund of Eskisehir Osmangazi University (BAP 201723A123). The authors are grateful for the support of the staff and facilities of the Department of Animal Science, Faculty of Agriculture, Eskisehir Osmangazi University.

\section{Authors' Contributions}

CKB was responsible for the concept, formulation of objectives and scope of research, formulation of conclusions, and creation of the publication text. SK co-conducted the laboratory studies and implementation of the research.

\section{Conflict of Interest Declaration}

The authors declare that they have no competing interests.

\section{References}

Abdulkarimi, R., Shahir, M.H. \& Daneshyar, M., 2019. Effects of dietary glutamine and arginine supplementation on performance, intestinal morphology and ascites mortality in broiler chickens reared under cold environment. Asian-Australas. J. Anim. Sci. 32, 110-117.

Atan, H. \& Kop-Bozbay, C., 2019. In ovo injection of beta alanine: Performance, meat quality and some blood parameters of broiler chicks. 11. Int. Anim. Sci. Cong, Cappadocia, Turkey. Pp. 88-92.

Awad, W.A., Bohm, J., Razzazi-Fazeli, E., Ghareeband, K. \& Zentek, J., 2006. Effect of addition of a probiotic microorganism to broiler diets contaminated with deoxynivalenol on performance and histological alterations of intestinal villi of broiler chickens. Poult. Sci. 85, 974-979.

Awad, W.A., Ghareeb, K., Abdel-Raheem, S. \& Bohm, J., 2009. Effects of dietary inclusion of probiotic and synbiotic on growth performance, organ weights, and intestinal istomorphology of broiler chickens. Poult. Sci. 88, 49-56.

Barekatain, R., Chrystal, P.V., Howarth, G.S., McLaughlan, C.J., Gilani, S. \& Nattrass, G.S., 2019. Performance, intestinal permeability, and gene expression of selected tight junction proteins in broiler chickens fed reduced protein diets supplemented with arginine, glutamine, and glycine subjected to a leaky gut model. Poult Sci. 98, 6761-6771.

Bartell, S.M. \& Batal, A.B., 2007. The effect of supplemental glutamine on growth performance, development of the gastrointestinal tract, and humoral immune response of broilers. Poult. Sci. 86, 1940-1947.

Caspary, W.F., 1992. Physiology and pathophysiology of intestinalabsorption. Am. J. Clin. Nutr. 55, 299-308. 
Chen, W., Wang, R., Wan, H.F., Xiong, X.L., Peng, P. \& Peng, J., 2009. Influence of in ovo injection of glutamine and carbohydrates on digestive organs and pectoralis muscle mass in the duck. Br. Poult. Sci. 50, 436-442.

Dai, S.F., Wang, L.K., Wen, A.Y., Wang, L.X. \& Jin, G.M., 2009. Dietary glutamine supplementation improves growth performance, meat quality and colour stability of broilers under heat stress. Br. Poult. Sci. 50, 333-240.

Fischer da Silva, A.V., Majorka, A., Borges, S.A, Santin, E., Boleli, I.C. \& Macari, M., 2007. Surface area of the tip of the enterocytes in small intestine mucosa of broilers submitted to early feed restriction and supplemented with glutamine. Int. J. Poult. Sci. 6, 31-35.

Foye, O.T., Uni, Z., Ferket, P.R. \& McMurtry, J.P., 2006. The effects of amniotic nutrient administration, in ovo feeding of arginine and/or-hydroxy-beta-methyl butyrate (HMB) on insulin-like growth factors, energy metabolism and growth in turkey poults. Journal. Poult. Sci. 5, 309-317.

Gholipour, V., Chamani, M., Shahryar, H.A., Sadeghi, A. \& Aminafshar, M., 2018. Effects of dietary L-glutamine supplement on performance, characteristics of the carcase and intestinal morphometry in guinea fowl chickens (Numida meleagris). Ital. J. Anim. Sci. 18, 513-521.

Iji, P.A., Saki, A.A. \& Tivey, D.R., 2001. Intestinal development and body growth of broiler chicks on diets supplemented with non-starch polysaccharides. Anim. Feed Sci. Technol. 89, 175-188.

Kop-Bozbay, C. \& Ocak, N., 2019. In ovo injection of branched-chain amino acids: Embryonic development, hatchability and hatching quality of turkey poults. J. Anim. Physiol. Anim. Nutr. 103, 1135-1142.

Kop-Bozbay, C. \& Ocak, N., 2020. Posthatch development in response to branched-chain amino acids blend supplementation in the diet for turkey poults subjected to early or delayed feding. J. Anim. Plant Sci. 30, 10981105.

Kriseldi, R., Tillman, P.B., Jiang, Z. \& Dozier III, W.A., 2017. Effects of glycine and glutamine supplementation to reduced crude protein diets on growth performance and carcass characteristics of male broilers during a 41-day production period. J. Appl. Poult. Res. 26, 558-572.

Kucharska-Gaca, J., Kowalska, E. \& Dębowska, M., 2017. In ovo feding-technology of the future-a review. Ann. Anim. Sci. 17, 979-992.

Li, X. \& Velleman, S.G., 2009. Effect of transforming growth factor- $\beta 1$ on embryonic and posthatch muscle growth and development in normal and low score normal chicken. Poult. Sci. 88, 265-275.

Lobley, G.E., Hoskin, S.O. \& McNeil, C.J., 2001. Glutamine in animal science and production. Nutr. J. 9, $2525-2531$.

Maiorka A., 2003. Posthatching water and feed deprivation affect the gastrointestinal tract and intestinal mucosa development of broiler chicks, J. App. Poult. Res. 12, 483-492.

Maiorka, A., Silva, A.V.F., Santin, E., Dahlke, F., Bruno, L.D.G., Boleli, I.C., Macari, M. \& Trautenmuller, H., 2016. Effect of broiler breeder age and glutamine supplementation on the development of the intestinal mucosa of 7-day-old chicks. Braz. J. Poultry Sci. 18, 17-22.

Meijerhof, R., 2006. Chick size matters. Worlds Poult. Sci. J. 22, 30-31.

Murakami, A.E., Sakamoto, M.I., Natali, M.R.M., Souza L.M.G. \& Farnco, J.R.G., 2007. Supplementation of glutamine and vitamin $\mathrm{E}$ on the morphometry of the intestinal mucosa in broiler chickens. Poult. Sci. 86, 488-495.

Ohta, Y., Tsushima, N., Koide, K., Kidd, M. \& Ishibashi, T., 1999. Effect of amino acid injection in broiler breeder eggs on embryonic growth and hatchability of chicks. Poult. Sci. 78, 1493-1498.

Salmanzadeh, M. \& Shahryar, H.A., 2013. Effects of dietary glutamine addition on growth performance, carcass characteristics and development of the gastrointestinal tract in Japanese quails. Rev. Med. Vet. 164, 471-475.

Salmanzadeh, M., Ebrahimnexhad, Y., Shahryar, H.A. \& Ghaleh-Kandi, J.G., 2016. The effects of in ovo feeding of glutamine in broiler breeder eggs on hatchability, development of the gastrointestinal tract, growth performance and carcass characteristics of broiler chickens. Arch. Anim. Breed. 59, 235-242.

Soltan, M.A., 2009. Influence of dietary glutamine supplementation on growth performance, small intestinal morphology, immune response and some blood parameters of broiler chickens. Int. J. Poult. Sci. 8, 60-68.

Uni, Z., Gamot, S. \& Sklan, D., 1998. Posthatch development of mucosal function in the broiler small intestine. Poult. Sci. $77,75-82$.

Uni, Z. \& Ferket, P., 2003. Enhancement of development of oviparous species by in ovo feeding. U.S. Patent No. 6,592,878. US Patent and Trademark Office, Washington, DC.

Uni, Z. \& Ferket, P.R., 2004. Methods for early nutrition and their potential. Worlds Poult. Sci. J. 60, 101-111.

Uni, Z., Ferket, P.R., Tako, E. \& Kedar, O., 2005. In ovo feding improves energy status of late-term chicken embryos. Poult. Sci. 84, 764-770.

Watford, M. \& Wu, G., 2005. Glutamine metabolism in uricotelic species: Variation in skeletal muscle glutamine synthetase, glutaminase, glutamine levels and rates of protein synthesis. Comp. Biochem. Physiol. B. Biochem. Mol. Biol. 140, 607-614.

Wu, G., 2009. Amino acids: Metabolism, functions, and nutrition. Amino Acids 37,1-17.

Xue, G.D., Barekatain, R., Wu, S.B., Choct, M. \& Swick, R.A., 2018. Dietary L-glutamine supplementation improves growth performance, gut morphology, and serum biochemical indices of broiler chickens during necrotic enteritis challenge. Poult. Sci. 97, 1334-1341.

Yi, G.F., Allee, G.L., Knight, C.D. \& Dibner, J.J., 2005. Impact of glutamine and oasis hatching supplement on growth performance, small intestinal morphology ans immune response of broiler vaccinated and challenged with Eimeria maxima. Poult. Sci. 84, 283-293.

Youssef, S.F., Abd El-Halim, H.A.H., Wahba, F.A., El-Maged, A. \& Marwa, H., 2017. Effect of in ovo methionine, glutamine, carnitine or betaine injection on hatchability, growth performance and physiological state. Egypt. Poult. Sci. J. 37, 1273-1287. 